\title{
Vocabulary Acquisition in EFL: \\ A Literature Review of Innovative Vocabulary Teaching Strategies
}

\author{
Gede Sutrisna \\ Universitas Dwijendra \\ gedesutrisna@undwi.ac.id
}

\begin{abstract}
In language learning, it is important for teachers to have in-depth consideration on the strategy of teaching vocabulary. It is advised to choose a strategy which brings lots of benefits for students' vocabulary acquisition. The strategy not only should facilitate the students to achieve the learning objectives, but also provide them with enjoyable and meaningful activities. It must be able to challenge the students so that they can actively and creatively participate during vocabulary teaching learning process. When they are involved, they are receiving, understanding and using the material given. Those processes will effectively promote their comprehension and vocabulary development. The purpose of this paper is to explore three innovative strategies for teaching vocabulary: Flip-a-Chip, Word Ladders and The Ripple Effect.
\end{abstract}

Keywords: vocabulary acquisition, EFL, Flip-a-Chip, Word Ladders, The Ripple Effect

\section{Introduction}

As one of the language components, the role of vocabulary in language learning cannot be doubted. It is considered as essential element to build a good language competence. Its function is like a foundation of which determine the endurance of a building. A building may be easily collapse without a great foundation which supports the entire unit. Thus, without having adequate vocabulary, language learners will not be able to develop their language skills effectively (Rasouli \& Jafari, 2016).

Stæhr (2008) notes that students' vocabulary mastery defines the capability of the student to read, write, listen, and speak. It helps them understand the text in terms of reading ability. In addition, it enables them to transform their ideas into a wide-ranging sentence of the subject in writing (Sutrisna, 2019). Having sufficient vocabulary also makes it easier for them to explain their concepts verbally while speaking, as well as understand what other people are talking about while listening (Sutrisna \& Artini, 2020). Those capabilities could not be achieved if they have limited vocabulary. At the worst, it will bring difficulties for them to read and understand the spoken and written content and affect their capability to produce good writing and speech. Therefore, vocabulary mastery plays a crucial role in learning new language, more particularly foreign language. Foreign language teachers, i.e. EFL teachers should put it into main consideration as it leads the way which enables the students to express their thoughts and feeling, either in spoken or written form. In fact, it is impossible to conduct a meaningful 
way communication in foreign language without vocabulary.

Yet, teaching English vocabulary is not an easy to task. It is always challenging when it comes to involve students into engaging vocabulary activities. In conventional teaching and learning process, somehow the students are noticed to be low-motivated in developing their vocabulary mastery. They are reluctant to explore and find out the meaning of the words that they think difficult to understand. They seem do not care and skip the words they are not familiar with. Most of them are spoon-feed types in which they just wait for their teachers to explain and define the words. In addition, the words only remain in their shortterm memory because they only remember it during the learning process. As soon as they leave the class, it would be gone by the wind.

Furthermore, the way most of the teachers teach vocabulary also affects the students' vocabulary development. They are noticed to teach all language skills, yet rarely enrich their students' vocabulary by discussing deeply the vocabulary involved within. Lecturing is found to be the common strategy used in which they just explain the words and its meaning without further follow up. What they might not realize is that teaching vocabulary is not merely about introducing the words, explaining its meaning to the students and having them memorize the words. Teaching vocabulary is more about encouraging the students to be words' lovers and involving them to fit the words into the world. Thus, they need a more innovative strategy which involves the students in an enjoyable and meaningful vocabulary learning process. This paper aims at exploring three innovative strategies for teaching vocabulary. The explanation covers the basic concept, procedures, strengths and weaknesses of each strategy.

\section{Discussion}

\subsection{Flip-a-Chip}

\section{A. The Basic Concept of Flip-a-Chip}

Flip-a-Chip is a strategy which originally developed by Lee Mountain, a Professor at University of Houston, to promote students' vocabulary development. This strategy is highly recommended for those who want to teach vocabulary creatively and meaningfully (Purwanto, 2020). It is a new brand innovative strategy to teach as well as enrich vocabulary which makes the learning activity comes into alive. Unlike the conventional strategy in which students are spoon-feed, this kind of strategy allows the students to discover, produce and learn vocabulary by their own within an enjoyable activities. Students are involved to place letter or words on each side of the two chips before flipping them to produce new words. This activity gives the students opportunity to reveal any possible words from the combination of the flipped chips. It not only lets students practice in fun way, but also challenges them to be creative during learning. In addition, it is also 
believed that this strategy manage to motivate students in learning. During the activities, what teachers need to do is to facilitate and guide the students while discovering the words from the two flipped chips. They need to clarify the meaning as well as the use of the words discovered by the students. It needs to be done because we should keep them in the track and make sure that they are not falling into confusion.

Mountain (2002) further asserts that this innovative strategy relies on student involvement in the activity and requires student participation, which enhances personal engagement in the activity and leads to deeper processing of word, more particularly the ones related to verb combinations with ing and -ed, -es and -s; adjective combinations with -er and -est; noun combinations with apostrophe $s$ and plural $s$, and even the plural possessive $s$; and mixed combinations of frequently used syllables (e.g., a prefix and a root). Mountain claims that teaching prefixes (e.g. de-, ex-, im, re-, sup, trans-) and roots (e.g. port) is important due to their high frequency in English words. She also believes that being familiar with the high frequency roots allows students to improve their comprehension of numerous words.

Last but not least, Flip-a-Chip can be used to teach advanced morphology. Mountain implies that this strategy can bring the students better insight to how change a word into different part of speeches. For instance, the adjectives like fearful, fearless, helpful, helpless can be formed by combining suffixes like -ful and less with other words like fear and help. She further claims that this activity gives a challenge for the students to fit the words (prefix, root, and suffix) together meaningfully.

\section{B. Procedures of Flip-a-Chip}

Practically, the basic principle of Flip-a-Chip allows the students to discover, produce and learn vocabulary by their own within enjoyable activities. As summarized in Mountain's Journal of Adolescent \& Adult Literacy (pp. 62-68), she implicitly elaborates Procedures in conducting Flip-a-Chip as follows.

1) Prepare a collection of chips. Mountain (2002) used poker chips but any chips or any hard circles are usable.

2) Model the students how this strategy works by showing them two chips in which each side of the chip has different words. For instance, $P R O$ on the front, and $R E$ on the back side of the first chip; DUCE on the front and VOKE on the back side of the second chip. For beginner level, you may provide the easier one (ex: $C$ on the front and $M$ on the back side of the first chip; then, $-A T$ on the front and $-A P$ on the back side of the second chip). See figure. 1 and 2 for how to label the chips. 


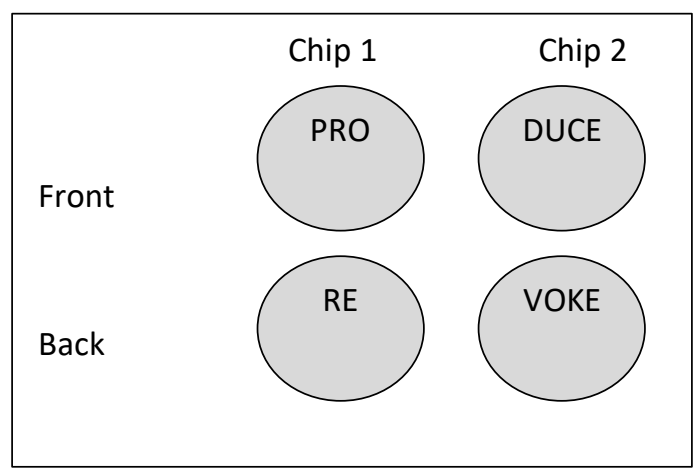

Figure 1. Flip-a-Chip labeling sample

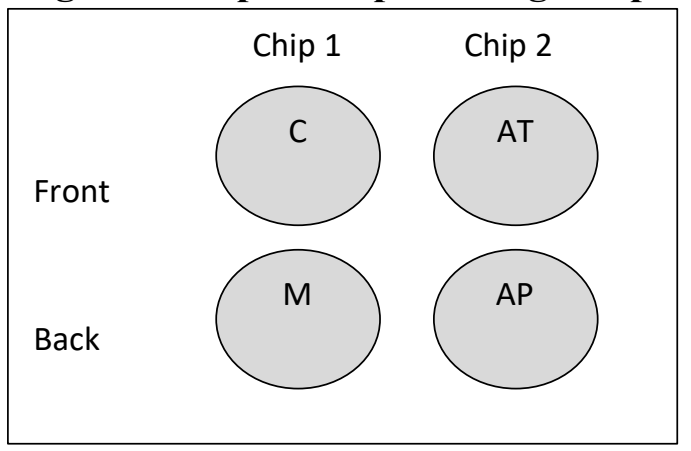

Figure 2. Flip-a-Chip labeling sample (Beginner level)

3) Flip the two chips in the air.

4) When the two chips land, show the students that the combinations make words. For instance, the two chips show PRO + VOKE (provoke), PRO + DUCE (produce), $\mathrm{RE}+\mathrm{VOKE}$ (revoke), and RE + DUCE (reduce). Another example, particularly for the easier one can be elaborated as follows: $\mathrm{C}+\mathrm{AT}$ (cat), C + AP (cap), M + AT (mat), $\mathrm{M}+\mathrm{AP}$ (map).

5) After the initial introduction of Flip-a-Chip, let the students try this activity. Have them explore every possible word combinations.

6) Once the words have been discovered, discuss their meanings clearly.
7) Provide any exercise which can be used to reflect students' mastery level.

\section{Strengths and Weaknesses of Flip-a-Chip}

None of the applied strategies is perfect. Every strategy must have its own good and bad in common. Like other strategy, Flip-a-Chip has several strengths and weaknesses for its implementation in vocabulary teaching learning. As implied in Mountain's journal (2002), the strengths and weaknesses of Flip-aChip can be presented as follows.

\section{- Strengths of Flip-a-Chip}

- Create a pleasantly literate environment in the classroom. The students are not only listening to the teachers' explanation, but also participating actively during the activities of word discovery.

- Bring excitement to the students. The more creative the chips, the more likely students are to get excited to use them.

- Great to use for practice of spelling words and to develop reading skills.

- Applicable for all levels in which scaffolding of words and levels is encouraged.

- Suitable for both small and large number of class.

- Weaknesses of Flip-a-Chip

- Need further adjustment for students who have visual 
impairment (using larger chips with bolder fonts) and for those with auditory impairments (using a microphone and read out loud the chips that are flipped).

- Need further clarification to make sure the mix-matching of the flipped chips does not bring confusion to the students.

\subsection{Word Ladders}

\section{A. The Basic Concept of Word Ladders}

As an innovative teaching vocabulary strategy, Word Ladders is a strategy which actively involves each learner in analyzing the structure and meaning of words. Rasinski (2008) points out that Word Ladders is effective in developing students' decoding and vocabulary skills. It builds breadth and depth into students' vocabulary knowledge. The activities also require students to examine subtle difference between words.

According to Fatahussalam (2018), Word Ladders are powerful tools for teaching students about the relationships among synonyms and antonyms. Therefore, this strategy is believed to effectively promote students' comprehension upon the meaning and concept of words as well as to increase their vocabulary. In addition, Word Ladders brings such fun activities to improve students' spelling skills. Last but not least, practicing or working with Word Ladders should transfer to critical reading and to strengthening students' word choice to add precision and detail to their writing.

The application of this strategy could be done seamlessly. Students are given one word or key phrase, and then they are required to make a series of other words by changing or rearranging the letters in the word before. The letters in the key phrase are used to compose new words based on teacher prompts and hints. For instance, students are given the word walk. Then, they are given hints to change one letter in walk to make a word that means "to speak." The word students will make, of course, is talk. The next hints for the next word will then ask students to make a change in talk to form another wordperhaps tale, or tall. Students will form new words as they work up the ladder until they reach the top rung.

\section{B. Procedures of Word Ladders}

As adapted from Rasinski (2008), implementing Word Ladders in vocabulary teaching learning require several steps as follows.

1) Choose whether you want to do your Word Ladders with the class as a whole, or by having students work alone, in pairs, or in groups.

2) Write the key phrase on the board and have the students copy it onto their paper (or are given letter tiles to construct it). For example: "Team to Work"

3) At each new word, students will be given two hints: the kinds of changes they need to make to the previous word ("rearrange letters" or "add two letters"), and a definition of or clue to the 
meaning of the word. Sometimes this clue will be a sentence in which the word is used in context but is left out for children to fill in. For example:

- Hints: (1) Rearrange the letters in 'Team' to make a word that means (2) the food that comes from animals. [Answer: Meat]

- Hints: (1) Rearrange the letters in Meat to make a word that means (2) not wild. [Answer: Tame]

4) Move from word to word this way, up the whole Word Ladders.

5) Give feedback to the students throughout the lesson.

\section{Table 1. Sample of Word Ladder}

\begin{tabular}{|c|c|c|}
\hline Work & $\begin{array}{l}\text { Change } \\
\text { one letter. }\end{array}$ & $\begin{array}{l}\text { What teams } \\
\text { must do } \\
\text { together. The } \\
\text { coach said to } \\
\text { us, "Good__ ' } \\
\text { team!" }\end{array}$ \\
\hline Worn & $\begin{array}{l}\text { Change } \\
\text { one letter. }\end{array}$ & $\begin{array}{l}\text { Something gets } \\
\text { _out when it } \\
\text { has been used } \\
\text { often. }\end{array}$ \\
\hline Torn & $\begin{array}{l}\text { Add one } \\
\text { letter. }\end{array}$ & Ripped. \\
\hline Ton & $\begin{array}{l}\text { Take away } \\
\text { two } \\
\text { letters, } \\
\text { then add } \\
\text { one. }\end{array}$ & $\begin{array}{l}\text { An enormous } \\
\text { weight: } 2,000 \\
\text { pounds. }\end{array}$ \\
\hline Toll & $\begin{array}{l}\text { Change } \\
\text { one letter. }\end{array}$ & $\begin{array}{l}\text { What you pay } \\
\text { to cross a } \\
\text { bridge. }\end{array}$ \\
\hline Tall & $\begin{array}{l}\text { Change } \\
\text { one letter. }\end{array}$ & Not short \\
\hline Tale & Change & A story \\
\hline
\end{tabular}

\begin{tabular}{|c|c|c|}
\hline & one letter. & \\
\hline Take & $\begin{array}{l}\text { Change } \\
\text { one letter. }\end{array}$ & $\begin{array}{l}\text { To get or bring } \\
\text { something. }\end{array}$ \\
\hline Tame & $\begin{array}{l}\text { Rearrange } \\
\text { letters }\end{array}$ & Not wild \\
\hline Meat & $\begin{array}{l}\text { Rearrange } \\
\text { letters }\end{array}$ & $\begin{array}{ll}\text { Food } & \text { that } \\
\text { comes } & \text { from } \\
\text { animals. } & \end{array}$ \\
\hline Team* & & \\
\hline $\begin{array}{l}{ }^{*} \text { Key } \\
\text { phrase }\end{array}$ & $\begin{array}{l}\text { Letter } \\
\text { Changes } \\
\text { (\#1 Hint) }\end{array}$ & $\begin{array}{l}\text { Definition or } \\
\text { Meaning } \\
\text { Hint })\end{array}$ \\
\hline
\end{tabular}

\section{Strengths and Weaknesses of Word Ladders}

- Strengths of Word Ladders

Teaching vocabulary by using Word Ladders is like bringing pleasing games to the students. As summarized from Rasinski's book (2008), he elaborates several strengths of Word Ladders that might attract the readers to implement this kind of strategy. Here they are presented briefly as follows.

- This strategy is great for building students' decoding, phonics, spelling, and vocabulary skills. When students add or rearrange letters to make a new word from one they have just made, they must examine soundsymbol relationships closely. This is just the kind of analysis that all children need to do in order to learn how to decode and spell accurately. 
- This strategy helps extend students' understanding of words and concepts since the puzzle adds a bit of meaning in the form of a definition (for example, "make a word that means to say something")

- Word Ladders enables the students to practice essential literacy skill unconsciously due to its game-like implementation.

- This strategy can help the students deepen their understanding of word relationships by having them sort the words into various categories. For instance, they could sort them into:

- Grammatical categories. (Which words are nouns? Verbs?)

- Word structure. (Which words have a long vowel and which don't? Which contain a consonant blend?)

- Word meaning. (Which words express what a person can do or feel? Which do not?)

\section{- Weaknesses of Word Ladders}

Like any other strategy, despite having numerous strengths, Word Ladders has several weaknesses as well. As implied in Rasinski's book (2008), the weaknesses of Word Ladders can be elaborated as follows.

- Students may have difficulty with certain words especially the ones which have multiple meanings. If it happens, they are likely stuck on particular rung of the Word Ladders.

- Each time students generate a new word, teachers need to check and clarify whether it has correct spelling and fulfill what is required by the hints.

- Sometimes the activity may take much longer especially for those who have insufficient prior vocabulary knowledge and they do not understand the hints given.

\subsection{The Ripple Effect}

\section{A. The Basic Concept of The Ripple Effect}

The conventional vocabulary teaching learning sometimes only facilitates the students to know and understand the meaning of a word. It does not elaborate that English vocabulary is the phenomenon of polysemy in which one word has more than one meaning. For instance, the word book has different meanings for different context. Mainly, it means a compilation of paper which contains written information, stories, etc. Then, its other meaning is to reserve something. Such case often leads the students into great confusion and frustration during EFL/ESL learning.

Based on the elaborated issues, Fengying (1996) developed an innovative strategy called The Ripple Effect. She believes that implementation of this strategy can help the students become aware that the majority of the English words have more than one meaning. As implied in Fengying's article entitled 
The Ripple Effect: Word Meaning Expansion and Its Application in Teaching Vocabulary; the concept of this strategy is grounded on which word-meaning expansion works like a ripple, which starts from a center and extends outward. In this strategy, the ripple diagram can link the original denotation and its metaphorical extension. With the help of the diagram, the relationship between the core meaning (original meaning) and its expansion meaning can be clearly seen. Thus, comprehension and retention will be made much easier for the learners.

\section{B. Procedures of The Ripple Effect}

Fengying (1996) states that the ripple diagram for The Ripple Effect can be easily made once students are familiar with the concepts and the technique. As implied in her article, the implementation of this strategy requires several steps as follows.

1) Decide whether the students should work individually or in groups;

2) Deliver the words that they should work for;

3) Encourage them to work with the help of dictionary or any available resources. In this part, let them think for themselves;

4) Once they have done searching for the resources, ask them to create the three layers ripple diagram in detail by noting these aspects:

a) What the core meaning is;

b) The extension meaning of the core in the next layer consisting of the inner layer and the outer layer (abstract ideas)

5) Allow students to differentiate the three layers by using color so that they can clearly see the expanded meaning areas of the word related to the original core.

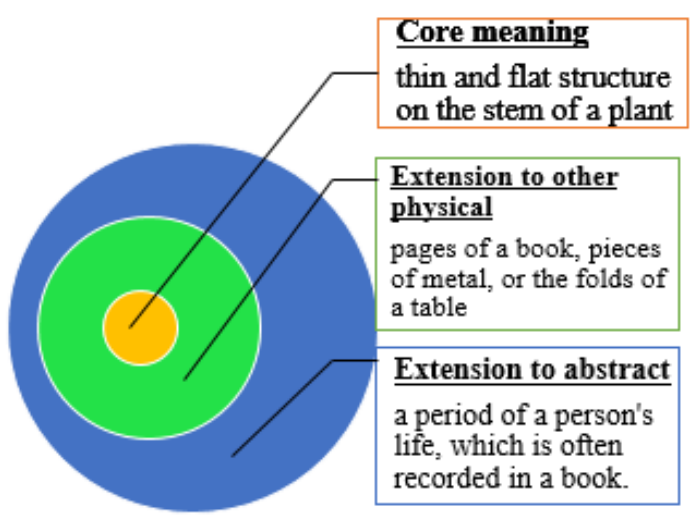

Figure 3. The meaning expansion of the word "leaf" by using ripple diagram

The figure above is an example of ripple diagram construction which is adapted from Fengyin's article (1996). It illustrates how the meaning for the word leaf expands into other meanings. The core meaning of leaf is the thin and flat structure on the stem of a plant. From that comes the next layer of meanings such as pages of a book, pieces of metal, or the folds of a table. It is then extended to abstract ideas such as a period of a person's life, which is often recorded in a book. Hence, there are phrases like "turn over a new leaf," or "take a leaf out of somebody's book."

\section{Strengths and Weaknesses of The Ripple Effect}

- Strengths of The Ripple Effect

The implementation of The Ripple Effect (the ripple diagram) is 
found to have some considerable merits.

- It is a powerful strategy that focuses on vocabulary comprehension, retention, and production, it enables students to learn how to make associations and to use their imaginations in the learning process.

- It gives students better understanding of a word. The diagramming can illustrate not only many meanings of a word, but also the links between those meanings. In addition, it can also demonstrate collocations and idiomatic usage. Through the links provided in a diagram, students will more easily understand an abstract or alien concept.

- This strategy is useful in fostering target-culture awareness. Metaphorical thinking and language use are universal, but the actual associations are culturespecific. In diagramming the links between the meanings of a word, the teacher is also leading students to look at the world in the same way that native speakers do. This is especially true of collocations, set expressions, and idioms.

- This strategy of vocabulary comprehension can be incorporated into different stages of reading: Beforereading to wipe out possible obstacles; while-reading to aid comprehension; after-reading to reinforce the words learned.

- Weaknesses of The Ripple Effect

- It might not be appropriate to illustrate a verb in which actions are more effective to use.

- It requires different treatment for different types of term.

\section{Conclusion}

The discussion of this paper focuses on three innovative strategies that can be carried out in teaching vocabulary. From the discussion, we understand that Flip-a-Chip is a new brand innovative strategy which allows the students to discover, produce and learn vocabulary by their own within enjoyable activities. This kind of strategy gives the students opportunity to reveal any possible words from the combination of the flipped chips. It not only lets students practice in fun way, but also challenges them to be creative during learning. More particularly, this strategy has been successfully proven as a tool to teach syllables, comprehension of meaningful affixes, and the use of context in composition. Another innovative strategy, Word Ladders actively involves each learner in analyzing the structure and meaning of words. This strategy is not only effective to develop students' decoding and vocabulary skills, but also to promote students' comprehension upon the meaning and concept of words. The last strategy discussed is The Ripple Effect. It is a powerful strategy in 
vocabulary

comprehension, retention, and production. This kind of strategy enables students to learn how to make associations and to use their imaginations in the learning process. The implementation of this strategy can give students better understanding of a word. The diagramming can illustrate not only many meanings of a word, but also the links between those meanings. In addition, it can also demonstrate collocations and idiomatic usage.

\section{References:}

Fengying, M. (1996). The ripple effect: Word meaning expansion and its application in teaching vocabulary. Vol. 34, No.1, p.8. Retrieved from

http://dosfan.lib.uic.edu/asia/EUSIA/forum/vols/vol34/no1/p8. htm

Fatahussalam, R. (2018). Increasing vocabulary by using word Ladder as the game for young learners (Diploma thesis). Bandung: UIN Sunan Gunung Djati Bandung

Mountain, L. (2002). Flip-a-Chip to build vocabulary. Journal of Adolescent and Adult Literacy, 46(1), 62-68. Retrieved from http://specialprograms.pbworks .com/f/Flip+a +chip.pdf

Purwanto, M. B. (2020). Teaching Prefixes as Part of Teaching Vocabulary by Using Flip-AChip to The Eleventh Grade Students of Senior High School $\begin{array}{lll}\text { Aisyiyah } & 1 & \text { Of }\end{array}$ Palembang. Esteem Journal of English Education Study Programme, 3(1), 34-41.
Rasinski, T.V. (2008). Daily word ladders: Grades 1-2. USA: Scholastic Inc. Retrieved from http://www.scholastic.com/teac hers/article/collateral_resources/ pdf/07/9780545194907.pdf

Rasouli, F., \& Jafari, K. (2016). A deeper understanding of L2 vocabulary learning and teaching: A review study. International Journal of Language and Linguistics, 4(1), 40-46.

Stæhr, L. S. (2008). Vocabulary size and the skills of listening, reading and writing. Language Learning Journal, 36(2), 139-152.

Sutrisna, G. (2019). Promoting students 'descriptive paragraph writing competence through picture drawing dictation technique (PDDT). Widya Accarya, 10(2).

Sutrisna, G., \& Artini, L. P. (2020). Does Problem-Based Learning Affect Students' Speaking Skill and Attitude toward ELL?. RETORIKA: Jurnal Ilmu Bahasa, 6(2), 131-138. 